\title{
Modeling the sustainable performance of residential building envelope: the role of performance indicator
}

\author{
A. Mwasha, R. Williams \& J. Iwaro \\ Department of Civil and Environmental Engineering, \\ University of West Indies, Trinidad and Tobago
}

\begin{abstract}
The success of modeling the sustainable performance of a residential building envelope will be, to a great extent, associated with the sustainable performance indicative parameters used. The sustainable indicative parameters that these assessment models are developed around should be chosen taking into account the targeted objectives. However, it is very common to find building performance assessment models that do not take into account these considerations and therefore have a limited capability and scope. The focus of this paper is to investigate the principal sustainable performance indicators for modeling the sustainable energy performance of the residential building envelope. This paper also provides an overview of existing sustainable performance indicators, discusses a conceptual framework for developing indicators and how they can be determined. In order to identify these indicators that influence the capability of building assessment models, a comprehensive survey of construction industry professional was conducted using questionnaire survey technique, while the data was analyzed using correlation analysis techniques. Suggestions were made on the principal sustainable performance indicator parameters that should be incorporated into the sustainable performance model.
\end{abstract}

Keywords: building, envelope, sustainable, performance, indicator, energy, efficiency, model, residential, decision, framework. 


\section{Introduction}

Building performance assessment methods are an effective means of assessing the sustainable performance of buildings, but required appropriate, sustainable indicators for specific objectives. According to Hensen and Harputlugil [1] and Kibert [2] BREEAM assesses the performance of buildings using the following assessment criteria, such as management; energy use; health and well-being; pollution; materials: environmental implication of building materials; water: consumption and water efficiency. While in the case of LEED, it is structured with seven prerequisites and a maximum of 69 points divided into six major categories: sustainable sites; water efficiency; energy and atmosphere; materials and resources; indoor environmental quality; innovation and design process $[1,3]$.

The above information and the literature review on building assessment tools show a variation in sustainable indicators used in some of these tools and a high level of complexity. In the past several years, many building and environmental assessment systems for buildings have been built, including the BREEAM in U.K, the LEED in U.S.A, the QUANTUM in Netherlands, the PromisE in Finland, the ECO-PRO in Germany, the EQUER in France, the CASBEE in Japan and the Athena in Canada etc. These assessment methods vary in scope, structure, format and complexity and sustainable determinants used.

There is not any assessment tool which could be widely used in the world until the birth of GBTool. In order to develop a universal method for measuring building performance across a range of environmental issues, the Green Building Tool (GBTool) assessment framework came into being [4]. It was collaboratively developed by 19 countries, it can be regarded as an international building environmental assessment method and is applicable to different types of buildings as well. In GBTool assessment system, the building performance is structured hierarchically by criteria and sub-criteria based on different performance issues and categories, including resource consumption, loading, indoor environmental quality, service quality, economics, pre-operation management and commuting transport etc. [4]. It addresses not only the biophysical environmental issues in the most comprehensible and dynamic manner of all the evaluated methods but also all building performance areas and all stages of the building lifecycle. The customization of benchmarks and weighting system provides opportunities to make GBTool adaptable in different circumstance [4].

Although GBTool undoubtedly provide a systematic and useful approach for building assessment, many researchers have pointed out that building assessment system should be adjusted according to the background of a certain country and region [4]. Cooper [5] contends that such current international attempts at developing a universal, standardized method for assessing the environmental performance of buildings are inherently flawed. He argues that such methods are found wanting in that they are culturally implicit, and that such methods or tools treat the sustainability of the built environment as simply a matter of energy and mass flows without due regard to the socio-economic and political dimensions of 
sustainability [5]. An idea sustainable performance decision making model will incorporate all relevant indicators in order to adequately assess the performance of the residential building envelope for sustainable energy, efficient design of buildings, as well as reduce residential building energy consumption. Therefore, the objectives of this paper are to investigate the principal sustainable performance indicators for modeling the sustainable energy performance of the residential building envelope. In addition, this paper also provides the overview of existing sustainable performance indicators, how they can be determined and suggests those principal sustainable performance indicators that should be incorporated into the sustainable performance decision making model.

\section{Overview of sustainable performance indicators}

In investigating the principal sustainable indicators for envelope sustainable performance modeling, this section examines the sustainable performance indicators that can be used to assess building envelope energy performance. The construction process is especially harmful to the urbanized territories and environment. It includes numerous sources of pollution: the entire traffic-related pollution and noise, dust, etc. [7]. There are five aspects of environmental impact indicator [8]: a) energy efficiency which focuses on the approach that can be used in the building design and system selection to optimize the energy efficiency of buildings; b) water efficiency which focuses on the selection of water use efficiency during construction and building operations; c) environmental protection which focuses on the design, practices and selection of materials that would reduce the environmental impacts of built structures. d) Indoor environmental quality (IEQ) which focuses on the design strategies that would enhance the IEQ; includes air quality, thermal comfort, acoustic control and day-lighting; e) other green features which focuses on the adoption of green practices and new technologies that are innovative and have potential environmental benefits. Likewise, Lombera and Aprea [9] described environmental performance indicators as related to building materials as: use of minerals, land uses, acidification, eutrophication, ecotoxicity, climate change, ozone layer, breathing effects due to organic substances and ironic radiation. These indicators pointed out the relevant environmental impacts as related to material used in building construction.

Besides, in ranking the sustainable performance factors according to their statistical weights among all types of construction organisations revealed the ranking of sustainable factors as the following: energy, materials, pollution, water, health and well being, ecology and land use, and finally transport. This result located environmental factors such energy consumption higher than the social factors. In consideration of embodied energy, the measure of embodied energy within a building is also used as a major indicator of environmental impact. This measure considers all the energy used in production of building materials and construction of the building, as well as energy needed for disposal or recycling of materials. Since the consumption of energy is also related to the production of greenhouse gases, particulates, acid gases, volatile organic carbons 
and other air pollutants, this measure also provides an indication of the pollutants released through energy consumption. Therefore, embodied energy is often used as the major indicator for sustainability of buildings $[10,11]$. The use of energy alone has raised concerns that a number of environmental factors are not considered in sustainable performance assessment. Uher [12] points out that the buildings contribute significantly to the environmental burden, quoting Levin [13] for the following contribution levels: use of raw materials (30\%), energy $(42 \%)$, water $(25 \%)$ and land $(12 \%)$, and pollution emission such as atmospheric emissions $(40 \%)$, water effluents $(20 \%)$, solid waste $(25 \%)$ and other releases $(13 \%)$. Also, Boyle [11] indicated that the impact on the environment mainly resulted from pollutants, energy consumption, water consumption, land degradation/ consumption, resource consumption, waste production and loss of biodiversity incurred throughout the life cycle of buildings, from raw material extraction, processing, construction, building operation and demolition. As a result, few buildings can be considered sustainable, either in their construction, use of materials or operational lifespan. In consideration of varieties of indicator, the next section provides details of conceptual framework for the types of indicator framework available for sustainable performance appraisal.

\subsection{Conceptual frameworks for determining types of indicator parameters}

A number of different approaches have been developed for sustainable performance indicators, and the concepts underlying the framework in which the indicators are organised largely determine the selection of the types of indicators used [14]. Therefore, the section described in table 1 summarizes the characteristics of a number of well recognized sustainable performance indicator frameworks that can provide a platform from which to develop a framework suitable for building envelope sustainable performance appraisal. Six frameworks are presented table 1, such as the widely used pressure state response (PSR) variations, driving force state response etc [15].

Table 1: $\quad$ Conceptual framework for determining types of indicators.

\begin{tabular}{|c|c|c|c|c|c|}
\hline $\begin{array}{l}\text { Indicator } \\
\text { Type } \\
\text { Based }\end{array}$ & \multicolumn{2}{|c|}{ PSR variations } & $\begin{array}{c}\text { Project } \\
\text { Based }\end{array}$ & $\begin{array}{l}\text { Theme } \\
\text { Based }\end{array}$ & $\begin{array}{l}\text { Goal } \\
\text { Based }\end{array}$ \\
\hline $\begin{array}{l}\text { Pressure- } \\
\text { State- } \\
\text { Response } \\
\text { Frame } \\
\text { work }\end{array}$ & $\begin{array}{l}\text { Driving } \\
\text { Force- } \\
\text { State- } \\
\text { Response } \\
\text { Frame } \\
\text { work }\end{array}$ & $\begin{array}{c}\text { Driving } \\
\text { Force- } \\
\text { Pressure- } \\
\text { State- } \\
\text { Impact } \\
\text { Response } \\
\text { Framework }\end{array}$ & $\begin{array}{l}\text { Input- } \\
\text { Output- } \\
\text { Outcome- } \\
\text { Impact } \\
\text { Framework }\end{array}$ & $\begin{array}{c}\text { Issue or } \\
\text { Theme- } \\
\text { Based } \\
\text { Framework }\end{array}$ & $\begin{array}{l}\text { PICABUE } \\
\text { Framework }\end{array}$ \\
\hline
\end{tabular}

The Pressure State Response (PSR) framework is perhaps the most commonly used indicator framework [16]. It is useful as an indication of how policy analysts and engineers can bring about change to avoid, remedy or mitigates 
changes to the state of an existing resource or building value [17]. The model has however been widely criticized for being too simple, as it only assumes a three step linear sequence of causation [18]. The DPSIR model (Driving force-Pressure-State-Impact-Response) is yet another development of the PSR model that describes the casual chain of actions of environmental problems. The UNEP adopted this version for use in which it highlights the primary application of the PSR model as a tool for regional, national and global reporting and monitoring of environmental change. Its strengths appear to lie at this macro scale. Furthermore, project based frameworks are often used in monitoring the effectiveness of projects where the objective is to improve the state of the environment. However, the project cycle provides the framework. Also, output and impact indicators should be related in order to see the effectiveness of outputs for future reference $[14,15]$. On the other hand, the issue based frameworks focus on the environmental or sustainable development themes, rather than upon specific detailed dimensions of change. Indicators may be selected and organized according to major areas themes and sub-themes. This type of framework can also facilitate the identification of core issues for sustainability and is often more easily understood by the wider community [14].

The concept of sustainable envelope strives to make judicious use of the surrounding resources in order to create a harmonious environment and excellent living space for the dwellers, while minimizing the environmental impacts, ecological footprints and reducing energy consumption in building [17]. In the case of PICABUE framework, the equity principle in PICABUE framework deals with the principle of fair shares, both locally and globally, among the current generation. The principle of futurity is to ensure inter-generational equity within which a minimum environmental capital must be maintained for future generations. Also, the integrity of the ecosystem should be preserved and its value recognized and respected, in order not to disrupt the natural processes essential to human life and to protect biodiversity. The fourth principle PICABUE recognizes the importance of public participation in decisions concerning the process of sustainable performance indicator development [18, 19]. Moreover, the public participation factor is only found in the PICABUE model and it is concerned with the general public's participation in the decisionmaking process. Therefore, an integrated public participation, questionnaire survey was developed to obtain professional opinions from construction professional on the essential sustainable performance indicators that can be incorporated into this multi-criteria decision making model. The details can be seen in the next section.

\section{Methodology}

Questionnaire technique was used in this study to collect professional opinions from construction professionals while the preliminary data for questionnaire design was collected through literature reviewed. A total of 250 questionnaires were sent to construction professionals working in different organizations in Trinidad and Tobago's construction sector by posting and personal delivery. 
These participants were from both private and public organizations and a total of 82 completed questionnaires were returned which represented 33 percent response rate. This response rate is acceptable for research of this type. The aim was to obtain a general view of construction professionals; therefore a response rate of this nature is inevitable. Data was compiled with no consideration for the participants' age or educational background as participants might be unwilling to provide actual information.

\section{Data presentation and analysis}

Figure 1 below shows the distribution of respondents by profession and experience. The response rate of engineers, project managers and contractors constituted 72 percent while the remaining 28 percent were distributed among architects, environmentalist, consultants and others. Also, the survey shows the classification of the respondents' experiences in which 44 percent of the respondents have experience between 5 to 10 years while 17 percent have more than 10 year experience.

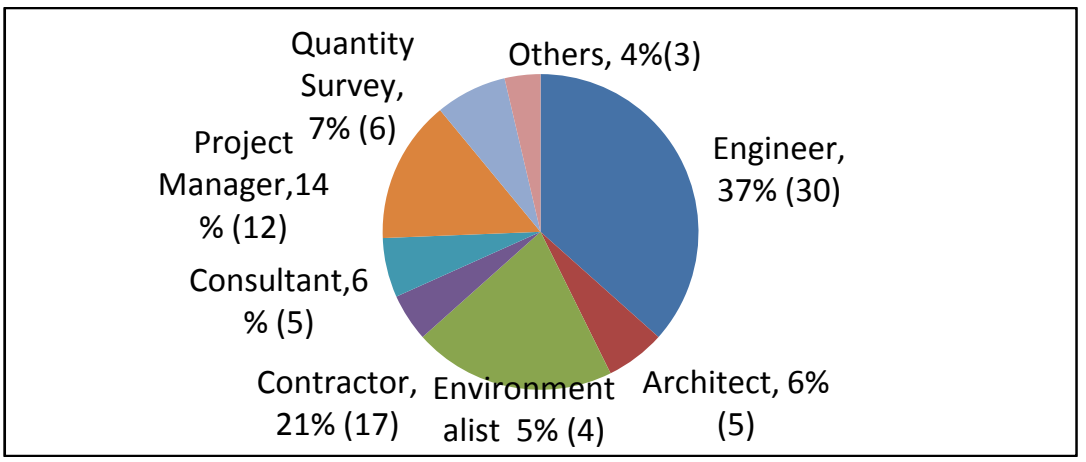

Figure 1: Distribution of respondent by profession and experience.

This shows that the outcome obtained from the survey represents the opinion of the construction professionals with good educational background, wealth of knowledge and experience needed in identifying sustainable energy performance criteria to be included in the sustainable performance decision making analytical model. Moreover, figure 2 shows the relative importance index based on the construction professional responses on the essential sustainable energy performance criteria to be incorporated in the sustainable performance decision making model. The rankings of the criteria are computed on the basis of the relative important index (RIIs) for each factor. The weighted average of the RII for each variable is computed by combining all the $\mathrm{RII}_{\mathrm{s}}$ and finds the weighted average by summing the products of the $\mathrm{RII}_{\mathrm{s}}$ for each group with the proportion of respondents from the corresponding group. The total weight for each criterion is calculated and a relative important index (RII) is constructed reflecting the level of importance of these criteria [20]. 


$$
\mathrm{RII}=\frac{\sum_{i=1}^{n} W i}{A N}
$$

where RII is relative importance index, $\mathrm{W}=$ weighting in eqn. (1) as assigned by each respondent on a scale of one to five with one implying "least important" and five "most important", $\mathrm{A}$ is the highest weight (5), $\mathrm{N}$ is the total frequency in the sample. The Kendall coefficient of concordance W, computed for ranking in figure 2, 3 and 4 based on total weighted scored for each group of professional which must be between 0 and +1 , is 0.7624 . This shows some consensus and association among the respondents. Also it indicates high level of correlation and dependency amongst the respondents on the sustainable performance appraisal criteria.

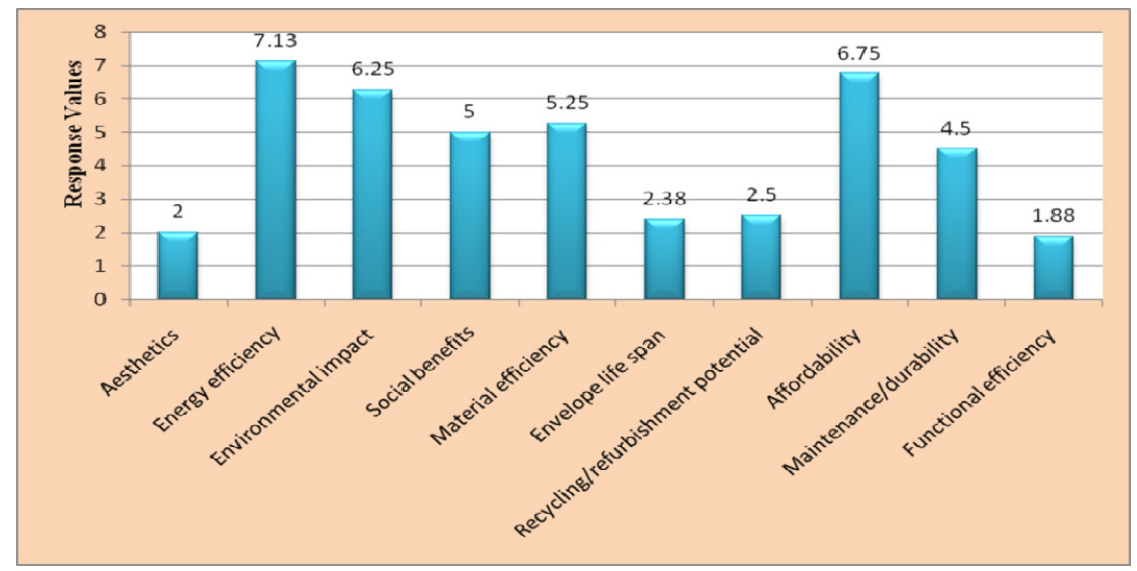

Figure 2: $\quad$ Ranking of sustainable performance appraisal criteria.

The Kendall coefficient of concordance W was used to determine the level of relationship amongst the ranking expressed by building and construction professionals. It is an index of actual agreement shown in the data from minimum agreement -1 to perfect agreement +1 [21]. Given the overall ranking obtained in figure 2 , the building and construction professionals recorded some levels of agreement about the importance of sustainable energy performance criteria in building envelope sustainable performance appraisal. Energy efficiency came first in the ranking order indicating the importance of energy and resource efficiency in sustainable development. For energy efficiency in building to be sustainable, other sustainable criteria have to be incorporated likewise and simultaneously. This is followed by affordability which means the building must be constructed at a lowest possible cost while still maintaining the sustainable standard and benefits. Also, this is followed other important sustainable criteria such as environmental impact, material efficiency, social benefits and maintenance/durability.

All these criteria are performance based criteria for sustainable performance appraisal of the building envelope. The ranking of the energy efficiency factors and material efficiency factors are presented in figure 3 and figure 4. According 


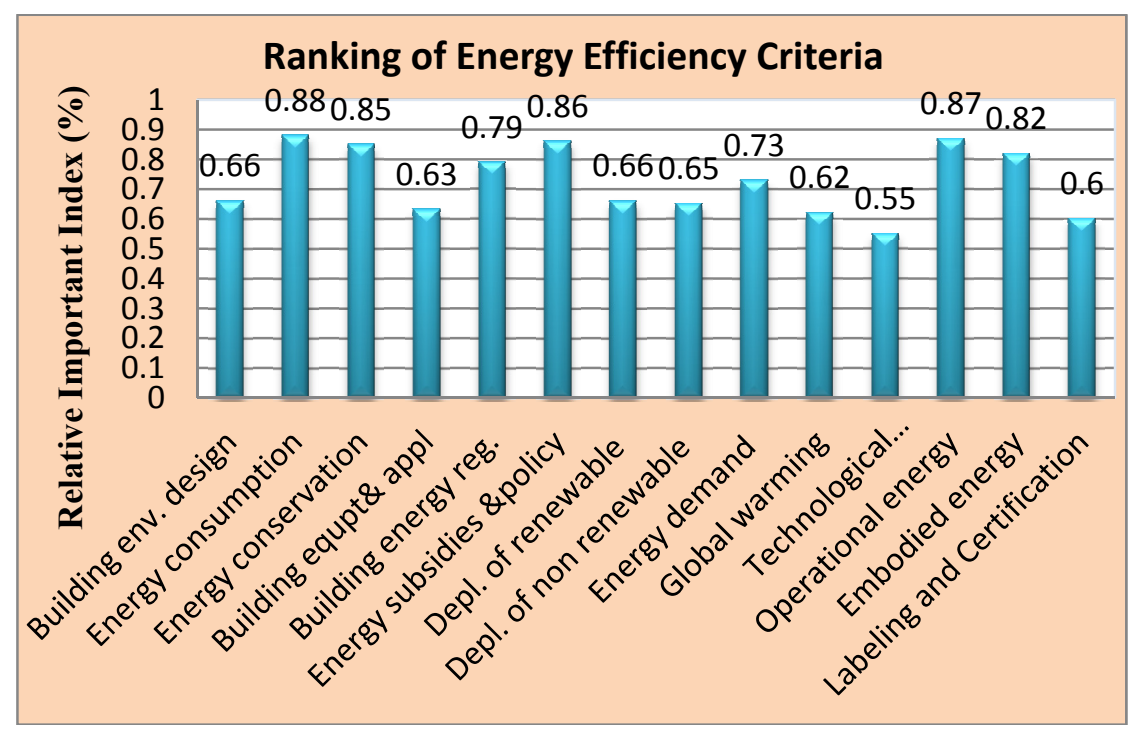

Figure 3: $\quad$ Ranking of energy efficiency criteria.

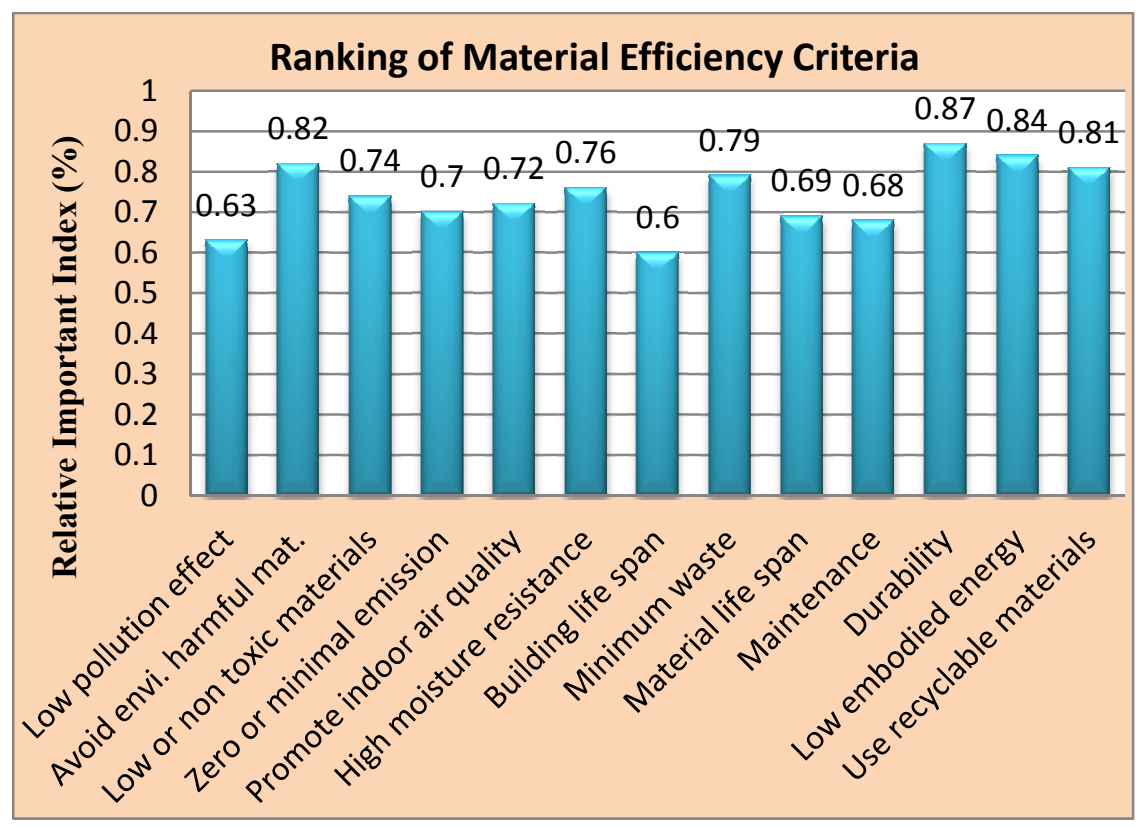

Figure 4: Ranking of material efficiency criteria. 
the above information, as shown in figure 3, energy consumption with relative important index (RII) 0.88 is the most important criteria influencing the sustainable performance of the building envelope. Other important factors identified are also related to energy consumption and serve as sub criteria such as operational energy, 0.85; energy subsidies, 0.86; energy conservation, 0.85 ; embodied energy, 0.84; energy demand, 0.73 and building energy regulation, 0.79. This shows that energy consumption is the most important indicator in building envelope sustainable performance appraisal. Also, it is the core issue on which other criteria identified above based. In the case of material efficiency material as shown in figure 4, durability is considered the most important criteria in assessing the sustainable performance of building envelope. This is followed by low embodied energy, use of recyclable materials; avoid environmentally harmful materials and minimum waste. Thus shows that material efficiency is an important indicator that needs to be assessed when appraising the sustainable performance of building envelope. The method and processes involved are discussed below.

\subsection{Measuring sustainable performance: using sustainable indicator parameters}

Stemming from a decades of effort to use metrics to measure sustainable indicator's phenomenon, hundreds of sustainable performance indicators for buildings and projects have sprung up all over the world. These buildings seek to move beyond a simple definition of sustainability, but to understand what it really means and how to measure it. There are several methods available to develop sustainable performance indicators based on the literature review conducted to study them all [22]. A method was developed which is largely based upon Gordon Mitchell's [23] work in the United Kingdom. In a broad sense, the community begins with the concept "sustainability", identifies its component parts (issues), selects indicators to accurately reflect the presence or absence of that dimension, and then evaluates the final indicator set. The specific steps of the method are as follows: Step 1 - Principles and definitions, Step 2 Selection of issues, Step 3 - Construction of indicators, and Step 4 - evaluation.

\section{Discussion}

The majority of sustainability assessment methods and frameworks as shown from the overview are developed using the three pillars models or the triple bottom line approach, where each pillar is separate but equally important to sustainability. However, the applicability of these model to the system's sustainability such as sustainable energy performance of envelope is doubtful because systems theory tells us that sustainability is dependent on the whole system's viability. To assess the sustainable energy performance of envelope, all other associated criteria have to be taken into consideration. This necessitates the move towards four dimensional sustainability assessments that incorporate energy and resources efficiency. 
In the survey carried out in this study to incorporate public and professional participation in setting out sustainable objectives and identified essential indicators for performance appraisal of residential envelope sustainable energy performance, significant agreement was received by energy efficiency, environmental impact, affordability, material efficiency, social benefits and durability as shown in figure 2. Energy efficiency came first in the ranking order indicating the importance of energy and resource efficiency indicator in sustainable performance appraisal. Further investigation on energy and material efficiency which is categorized under energy and resources sustainability, other sub criteria received significant agreement as well. The investigation revealed in figure 3 that energy consumption, energy conservation, energy subsidies\& policy, operational energy and embodied energy sub criteria are also important indicators under energy efficiency that have to be considered in appraising the sustainable energy performance of residential building envelope. Likewise, in figure 4, under material efficiency, durability, minimum waste, avoidance of environmental harmful material, low embodied energy, the use of recyclable material and pollution sub criteria also received significant agreement as essential sustainable performance criteria. These results collaborate findings from the overview conducted which indicated that sustainable energy performance has to be appraised by integrate performance indicators such as energy efficiency, energy consumption, environmental impact, affordability \& economic factors, social benefits, environmental benefits together and simultaneously. Other indicators identified from the overview include: biodiversity, waste product, resources consumption, and water consumption, and indoor air quality, use of recycled material, indoor pollution, embodied energy, operational energy material life span, operational life span and durability. This shows that the appraisal of residential envelope sustainable energy performance cannot be done in isolation but in consideration of other factors.

\section{Conclusion}

To realize sustainable construction, establishing sustainable building assessment method, a good assessment tool should be judged according to its potential application. In other words, it must be designed according to the local and regional situation from the guideline system to implementation strategies with incorporation of suitable sustainable indicators. This study has shown that sustainable indicators play a significant role in the formation a versatile sustainable performance decision making model that can adequately model the sustainable energy performance of residential building envelope and reduce building energy consumption. Hence, this aspect of sustainable indicator development as discussed above has summarized the essential components to be assessed in a building envelope sustainable performance appraisal. 


\section{References}

[1] Hensen Jan, Gülsu Ulukavak Harputlugil, The relation between building assessment systems and building performance simulation, 2010

[2] C.J. Kibert, High Performance Green Building, unpublished book draft, available from http://web.dcp.ufl.edu/ckibert/ASCEBook/index.htm, last accessed December, 2010.

[3] LEED., Leadership in Energy and Environmental Design online, LEED 2.1 Standard, available from: http://www.usgbc.org/LEED last accessed

[4] Qian Shi., Strategies of Implementing a Green Building Assessment System in Mainland China, Vol. 1, 2 , Journal of Sustainable Development 14, 2008

[5] I. Cooper., Which focus for building assessment methods - environmental performance or Sustainability. Building Research \& Information, 2 (1999) 321-331.

[6] Richard Hill, Sustainable building assessment methods in South Africa: an agenda for research, Paper presented at the International Conference on Sustainable Building, Oslo, Norway, 2002

[7] S. Mitkus, O.R. Shostak, Preservation of healthy and harmonious residential and work environment during urban development, International Journal of Strategic Property Management 13(4) (2009) 339-357.

[8] S.P. Low, J.Y. Liu, P. Wu, Institutional compliance and the Sino-Singapore Tianjin Eco-city Project, Facilities, 27(9/10) (2009) 368-386.

[9] J.T. Lombera, S. J. Aprea, A system approach to the environmental analysis of industrial buildings Building and Environment 45(3) (2010) 673-683.

[10] G. Treloar, P. Love, O. Faniran, Improving the reliability of embodied energy methods for project life cycle decision making. Logisticis Information Management 14 (2001) 303-317.

[11] C.A. Boyle, Sustainable buildings. Proceedings of the Institution of Civil Engineers Engineering Sustainability 158 March, Issue ES1,(2005) 41-48

[12] T.E. Uher, Absolute Indicators of Sustainable Construction. RICS Research Foundation, Royal Institution of Chartered Surveyors, London, 1999, available at http:// www.rics.org.uk/(accessed May 2010).

[13] H. Levin, Systematic evaluation and assessment of building environmental performance (ASEABEP). Proceedings of the 2nd International Conference on Buildings and the Environment, CSTB and CIB, 2, Paris, June 1997, 3-10, 1997

[14] L. Segnestam, Indicators of Environmental and Sustainable Development Theories and Practical Experience. The World Bank Environment Department, 2002

[15] Land Environment and People (LEAP)., Development of a Conceptual Framework for Sustainability Indicators Used in Structure Planning. Land Environment and People Research Report No. 13, May 2010, Lincoln University, Canterbury, New Zealand http://www.researcharchive.lincoln .ac.n2 /dspace/bitstream.pdf : 2010 
[16] Ministry for the Environment (.MFE)., Headline Indicators for Tracking Progress to Sustainability in New Zealand. Retrieved December 20, 2009, http://www.mfe.govt.nz/publications/ser/techreport-

[17] Unescap: Sustainable building design and planning http://Unescap.org /esd/energy/trade/cited 2010

[18] G. Mitchell, A. May, A. MacDonald, PICABUE: A methodological framework for the development of indicators of sustainable development. International Journal of Sustainable Development and World Ecology, 2 (1995) 104-123

[19] S. Curwell, I. Cooper, The implication of urban Sustainability in Building Research and Information 26(1998) 17-28.

[20] Environmental performance evaluation for construction. Building Research and Information 30(5) (2002) 349-361.

[21] Siegel, Sidney; N. John Castellan, Nonparametric Statistics for the Behavioral Sciences (2nd ed.). New York: McGraw-Hill. p. 266, 1988

[22] Devens Enterprise Commission., Sustainability Indicator, http://www.devensec.com/sustainreport.html /2010

[23] Mitchell, G., Problems and Fundamentals of Sustainable Development Indicators. Sustainable Development 4 (1996) 1-11, 1996 